\section{An automatic feeder for liquids and wet or dry solids}

\author{
HOWARD A. JEMISON III and ANDREW E. DIZON \\ Southwest Fisheries Center Honolulu Laboratory \\ National Marine Fisheries Service, NOAA \\ Honolulu, Hawaii 96812
}

and

MICHAEL M. WALKER

Department of Zoology

University of Hawaii, Honolulu, Hawaii 96822

An inexpensive and simple, remote-control conveyorbelt feeder is described. The feeder handles liquids and wet or dry solids.

Research on the magnetic sensitivity of tunas often requires remote-control feeders. Unfortunately, captive tuna only eat pieces of fish or squid that cannot be delivered by most commercially available feeders.

The feeders used in our research must be inexpensive and simple, since our resources and engineering capabilities are limited. The conveyor-belt feeders of Haralson and Ralph (1966) and Martin (1974) provide a model, but the feeder design described here is simpler, less expensive, and unique in its ability to handle liquids or wet or dry solids.

\section{THE FEEDER}

The feeder (Figure 1) consists of a conveyor belt mounted on a wooden $2.5-\mathrm{m}$ (8-ft) $2 \times 4 \mathrm{in}$. board. A longitudinal, $1.5 \mathrm{~cm}$ (deep) $\times 3 \mathrm{~cm}$ (wide) slot is cut as a guide for the belt. The groove diameter of the pulleys at each end is equal to the remaining thickness of the $2 \times 4$ in. wooden mount.

The pulleys are the most critical and difficult parts to build (Figure 1). The bottom of each pulley's groove is slightly humped to keep the belt aligned and is also knurled to provide sufficient grip on the belt. No bearings are used, since the duty cycle is short and rotational speeds are slow. The belt is made from 1 -in. wide Velcro ${ }^{1}$ tape, which is prestretched before the final sizing and sewing.

The containers can be small cups or vials, with small complementary circles of Velcro cemented or epoxied to the bottom of each. Using Velcro tape for the belt and on the containers allows the containers to be removed and refilled, cleaned, or replaced.

At one end of the feeder are mounted two aluminum plates that extend $15 \mathrm{~cm}$ beyond the end of the $2 \times 4$ in. wooden mount (see Figure 1). The plates serve as brackets for mounting one pulley, as well as a light and a photocell. The mounting holes are slotted to adjust



Figure 1. General view of feeder with a detail of the drive pulley.

belt tension. The light and photocell are mounted so that the container completely empties its contents before interrupting the photocell. The inside surfaces of the brackets are spray painted with flat black paint and the light source is collimated to reduce the possibility of glare and reflections inadvertently tripping the photocell.

On one side, at the opposite end of the feeder, is attached a larger bracket that serves as the mount for the motor and pulley. Since the opposite side need only hold the pulley, a $2.5-\mathrm{cm}$ aluminum channel is sufficient. A $22-\mathrm{rpm}, 3.5-\mathrm{cm}-\mathrm{N}$ (35-in.-oz), capacitorstart ac motor is connected directly to the pulley through the mounting plate. The feeder is mounted on a stand near its center of balance, and the stand is constructed so the feeder can be swung away from the tank for loading.

A "bridging" signal light is incorporated at the end of each feeder to alert the fish that a reward is forthcoming and to indicate to us the status of each feeder. This small ac light is placed in parallel with the ac motor on the outside of the photocell bracket. The light and motor turn on each time the feeder is activated.

Both control circuits are laid out and directly etched on one single-sided printed circuit (PC) board for simplicity (Figure 2, Detail A). The controller board and a $5 . \mathrm{V} 1.5-\mathrm{A}$ power supply are mounted in a $20 \times 20 \times 20 \mathrm{~cm}$ aluminum enclosure. The PC board is mated with an edge connector for easy removal.

As shown on the block diagram in Figure 2, Detail B, a switch closure from a pushbutton or a computeractuated relay applies a dc voltage to the controller, generating a digital pulse to tum the feeder on. This 


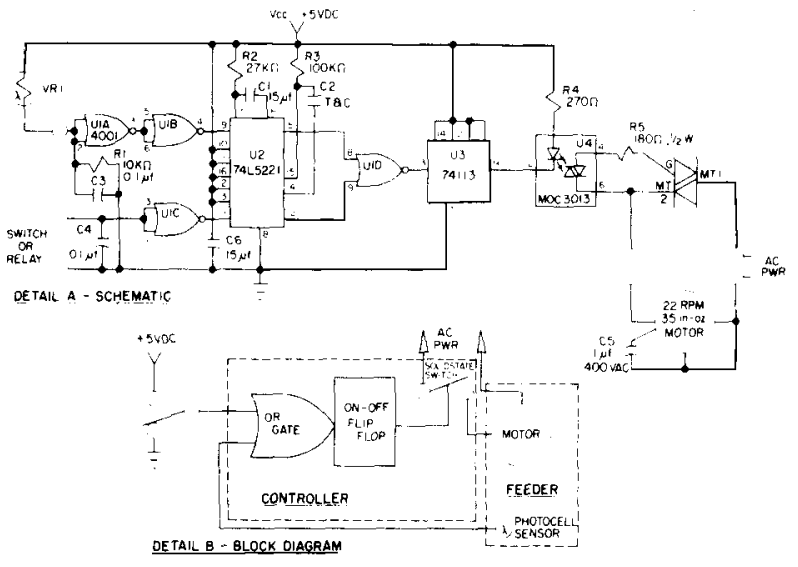

Figure 2. (A) Schematic diagram of the feeder controller circuit. (B) Circuit block diagram.

rotates a container around the end pulley, emptying its contents and interrupting a photocell. The controller, sensing the interrupt, stops the feeder. The input to the controller can also accept a TTL or CMOS pulse for initiating a cycle.
The load capacity is dependent upon the length of the $2 \times 4$ in. board and the container size. Our feeders use $2-\mathrm{cm}$-diam vials with a 5-cc capacity and hold approximately 50 vials. The containers can be of any shape, and different shapes and sizes can be used simultaneously.

Further details are available on request.

\section{REFERENCES}

Haralson, J. V., \& Ralph, G. S. A further improvement in the automatic dispensing of live food for fish. Journal of the Experimental Analysis of Behavior, 1966, 9, 153-154.

Martin, G. R. Two inexpensive raw meat dispensers. Behavior Research Methods \& Instrumentation, 1974, 6, 70-71.

\section{NOTE}

1. Reference to trade names does not imply endorsement by the National Marine Fisheries Service, NOAA.

(Received for publication December 21, 1981; revision accepted January 20, 1982.) 